\title{
SOME GOOD PLANT DEMONSTRATIONS THAT ARE NOT INCLUDED IN THE USUAL TEXT-BOOKS.
}

\author{
By F. L. Pickett, \\ High School, Bloomington, Ind.
}

I. The cobalt test for showing stomatal transpiration. Use leaf of Nerium, oleander, Ficus elastica, or any smooth begonia - preferably attached to a thriving plant. Attach strips of thoroughly dried cobalt paper to either side of the leaf by means of two thin object slides and small rubber bands. After IO-2O minutes the paper on the lower side of the leaf will show a decided pink tint and in many cases will have lost all appearance of blue, while the paper on the upper surface should show no change.

Previous examination. of these leaves-with the compound microscope-will have shown the presence of stomata on the under side and not on the upper. In order to make the experiment a success it is necessary to select a leaf for use on the upper side of which there are no stomata, or at least a very few stomata.

Caution: Use only smooth leaves, and be careful not to break the epidermis. It is almost impossible to prevent the crushing of plant hairs on leaves that have them.

Note: Cobalt paper is made by soaking clean filter paper in a 5-ro per cent solution of cobalt chloride and afterward thoroughly drying it.

This experiment is well known among plant physiologists, and has been much used since its presentation by Stahl in 1894. See also Detmer-Moor, 2nd Ed., pp. 214. It has not been recognized by authors of high school texts and manuals. To the writer it seems the simplest and most conclusive means of proving stomatal transpiration to elementary students.

2. To show the general fact of transpiration and the flow of water to leaves.

A vigorouns branch of Ricinus was attached to a glass tube which was drawn out to about I mm. diameter and placed in a roo cc. cylinder as shown in the figure. Attach the rubber connecting tube first to the glass tube, then by pressing the cork into the cylinder, the water may be forced up so there will be no air below the stem. Be careful to have the joints tied tightly or sealed with vaseline to allow no air bubble to remain in the connecting tube, and to have the cork fit loosely enough to allow air to enter to take the place of water flowing to the leaves. 